\title{
Treatment of Hazardous Waste by Carbon Dioxide Capture from an Electric Arc Furnace
}

\author{
Gustavo LEÓN, ${ }^{1)}$ Rodrigo CANTÚ, ${ }^{1)}$ Juan A. VILLARREAL, ${ }^{2)}$ Osvaldo M. MICHELOUD ${ }^{1)}$ and \\ Alejandro MONTESINOS-CASTELLANOS ${ }^{1 / *}$
}

1) Chemical Engineering Department, School of Engineering and Information Technologies, Tecnológico de Monterrey, Ave. Eugenio Garza Sada No. 2501, Col. Tecnológico, Monterrey, N.L., 64849 México.

2) Environmental Engineering Department, Ternium México, San Nicolás de los Garza, N.L., 66450 México.

(Received on June 10, 2014; accepted on November 3, 2014)

\begin{abstract}
The steel industry is important for the development of several economic activities in the world. Unfortunately, the electric arc furnace (EAF) used in production generates byproducts such as dust, which must be treated and confined to prevent pollution. In this study, the alkaline properties of solutions prepared with EAF dust were evaluated for use in $\mathrm{CO}_{2}$ capture. A process in which dust solution properties are regarded as an advantage is proposed. The results indicate that the developed process effectively minimizes operational problems. Specifically, the process neutralizes several hazardous pollutants contained in EAF dust, reduces $\mathrm{CO}_{2}$ emissions, and directly removes dioxin-forming dust from the exit gas stream.
\end{abstract}

KEY WORDS: $\mathrm{CO}_{2}$ capture; steelmaking industry; electric arc furnace dust.

\section{Introduction}

The electric arc furnaces (EAFs) used in the steelmaking industry can generate dust volumes of up to $10-20 \mathrm{~kg}$ per ton of steel produced, ${ }^{1)}$ and the global EAF dust production is estimated at around 3.7 million tons per year. ${ }^{2)}$ EAF dust is primarily used as a reprocessing material for zinc recovery or as a raw material for the construction industry. A significant problem is that dust not-compliant to specifications should be confined, with high costs.

An EAF is a flexible piece of equipment for steelmaking because it can melt scrap metal and/or direct reduction iron into steel products with several mass ratios. Given the increased focus on improving EAF technology in the past 30 years, the use of such equipment requires an investment cost that is less than that required for a blast furnace. ${ }^{3,4)}$ An EAF produces three main waste products: (1) gas, (2) slag, and (3) dust. Gases are produced by oxygen-induced chemical reactions in the EAF (e.g., carbon and natural gas combustion); at $\sim 1873 \mathrm{~K}$, the gases exit the EAF as $\mathrm{CO}_{2}, \mathrm{CO}$, $\mathrm{N}_{2}$, and $\mathrm{O}_{2}$ as main components. ${ }^{2)}$ Slag is produced during the melting process that generates a molten mixture of oxides (mainly $\mathrm{Ca}, \mathrm{Mg}, \mathrm{Si}$ and $\mathrm{Fe}$ oxides); because of its density, the mixture remains in the upper layer of the liquid steel bath. ${ }^{5)}$ Slag has a dual function in the melting process: (a) It controls the chemical composition of steel via the additives that affect the chemical equilibrium between steel and slag, and (b) as slag foam, it covers the electric arc, thereby decreasing the energy lost through radiation. ${ }^{5)}$

* Corresponding author: E-mail: alejandro_montesinos@itesm.mx DOI: http://dx.doi.org/10.2355/isijinternational.55.559
The dust produced during EAF operation is transported with the gases from the EAF via an extraction system and then recovered in a baghouse located downstream. The physical properties and chemical composition of the dust depend on the raw materials used in the process. For instance, when galvanized scrap is used as feedstock for EAF steel production, most of the zinc from the steel scrap is carried into dust because of the very low solubility of zinc in molten steel and slag and because zinc vapor pressure is higher than iron vapor pressure at steelmaking temperatures $(\sim 1873 \mathrm{~K})$. The chemical composition of the dust produced comprises simple and complex oxides of metals such as Fe, $\mathrm{Ca}, \mathrm{Na}, \mathrm{Mg}, \mathrm{Mn}, \mathrm{Si}$, etc. ${ }^{6,7)}$ whose origins have been previously reported. ${ }^{8)}$ EAF dust is a major issue in the production of industrial byproducts because it is difficult to recycle or reuse. As indicated in previous research, ${ }^{9)}$ less than $25 \%$ of EAF dust is used for zinc recovery or fertilizer production. An economically viable zinc recovery process necessitates dust with high zinc content ( $>20 \mathrm{wt} \%) .{ }^{9-14)}$

Most EAF dust is disposed of in landfills, but this approach is an unsuitable long-term solution because it presents environmental and management issues. EAF dust also contains hazardous elements (zinc, lead, cadmium, chromium, arsenic, etc.) that are unacceptable in landfills without previous treatment. To address these problems, researchers have proposed treatment measures, such as chemical stabilization or ferrous and nonferrous metal recovery (e.g., pyrometallurgical or hydrometallurgical processes)..$^{9,10,15-19)}$ Furthermore, EAF dust is involved in the formation of hazardous Cl-compounds, such as polychlorinated dibenzodioxins, polychlorinated dibenzofurans, and hexachlorobenzene. ${ }^{6}$ The formation these compounds can be decreased or pre- 
Table 1. $\mathrm{OH}^{-}$concentrations of EAF dust solutions estimated by $\mathrm{pH}$ measurements and concentration of bases from $\mathrm{HCl}$ titration.

\begin{tabular}{ccccccc}
\hline Sample & Wt. of dust & Wt. of water & $\begin{array}{c}\mathrm{pH} \text { measured } \\
\text { (fresh solution) }\end{array}$ & $\begin{array}{c}\mathrm{OH}^{-} \text {concentration } \\
\text { of fresh solution } \\
\text { (from pH measurement) } \\
\text { (mmol/l) }\end{array}$ & $\begin{array}{c}\mathrm{OH}^{-} \text {concentration } \\
\text { of fresh solution } \\
\text { from pH estimation } \\
\text { by ASPEN) (mmol/l) }\end{array}$ & $\begin{array}{c}\text { Concentration of bases } \\
\text { (from titration of fresh } \\
\text { solution) (meq/l) }\end{array}$ \\
\hline 1 & 5 & 95 & 12.87 & 74.1 & 144.4 & 90.0 \\
2 & 10 & 90 & 12.95 & 89.1 & 297.6 & 116.7 \\
3 & 15 & 85 & 13.22 & 165.9 & 470.4 & 250.0 \\
4 & 20 & 80 & 13.15 & 141.2 & 665.0 & 400.0 \\
5 & 25 & 75 & 13.24 & 173.7 & 886.0 & 526.7 \\
6 & 30 & 70 & 13.21 & 162.2 & 1140.4 & 533.3 \\
7 & 35 & 65 & 13.26 & 181.9 & 1439.6 & 600.0 \\
\hline
\end{tabular}

vented by dust removal from gases.

The discussion above shows that further investigation is needed, particularly on EAF dust processing because such treatment reduces or eliminates the problems associated with dust recycling or reuse, as well as its adverse effects on the steelmaking industry. Although EAF dust possesses harmful components, it also comprises substances such as calcium, sodium, potassium, and magnesium. These components have received less attention, yet they exhibit interesting properties that may be advantageous to steel production. For example, the interaction between EAF dust and water or wet air produces high-pH (up to 14) alkaline solutions that produce a high environmental impact. Motivated by this advantage, this study aims to measure the alkali content of several aqueous solutions synthesized with EAF dust and demonstrate the $\mathrm{CO}_{2}$ capture properties of the solutions. We also propose a simple process for neutralizing the harmful pollutants in EAF dust.

\section{Experimental}

\subsection{Synthesis of Solutions and $\mathbf{p H}$ Measurement}

The potential of dust as a component in the production of alkaline solutions was determined by preparing solutions with a 5-35 wt\% composition of dust in water, in accordance with the combinations in Table 1. A dust sample from a baghouse was used. The elemental analysis is presented in Table 2. The alkaline solutions were synthesized using the corresponding mass of dust and deionized water under magnetic stirring for $1 \mathrm{~h}$, and then the $\mathrm{pH}$ was determined by a Hanna Instruments pH211 microprocessor.

The $\mathrm{OH}^{-}$concentration was estimated by two methods: 1 ) from the direct $\mathrm{pH}$ measurements and the following equations:

$$
\begin{gathered}
p H=-\log _{10}\left[H^{+}\right] \ldots \\
p O H=-\log _{10}\left[O H^{-}\right] \\
p O H+p H=14
\end{gathered}
$$

2) Using the electrolyte NRTL model using ASPEN Plus V8 software. The estimations were carried out under the assumption that only the hydroxides of $\mathrm{Ca}, \mathrm{Mg}, \mathrm{K}$, and $\mathrm{Na}$ are responsible for $\mathrm{OH}^{-}$formation. Prior to the estimation, the conversion of the respective oxides and water into
Table 2. Average metal content of EAF dust used in this work.

\begin{tabular}{cc}
\hline Element & $\mathrm{mg} / \mathrm{kg}$ \\
\hline $\mathrm{Al}$ & 2686 \\
$\mathrm{Ba}$ & 34.1 \\
$\mathrm{Ca}$ & 31200 \\
$\mathrm{Cd}$ & 59.3 \\
$\mathrm{Cu}$ & 374 \\
$\mathrm{Cr}$ & 435 \\
$\mathrm{Fe}$ & 394700 \\
$\mathrm{~K}$ & 41030 \\
$\mathrm{Li}$ & 20.3 \\
$\mathrm{Mg}$ & 24890 \\
$\mathrm{Na}$ & 36790 \\
$\mathrm{Sr}$ & 30 \\
$\mathrm{Ti}$ & 526 \\
$\mathrm{~V}$ & 274 \\
$\mathrm{Zn}$ & 118700 \\
$\mathrm{~Pb}$ & 716 \\
\hline
\end{tabular}

hydroxides was verified. A conversion of nearly $100 \%$ was achieved.

\subsection{Titration with $\mathrm{HCl}$ or $\mathrm{CO}_{2}$}

Before the $\mathrm{pH}$ measurement, the alkaline solutions were neutralized by titration with $\mathrm{HCl}$ aqueous solution $(1 \mathrm{M})$. In a conventional procedure, $100 \mathrm{ml}$ of the alkaline solution was poured in an Erlenmeyer flask and then the $\mathrm{HCl}$ solution was added by dripping until a $\mathrm{pH}$ of 7 was reached, finally the solutions were aged for $24 \mathrm{~h}$. after the $24 \mathrm{~h}$ aging, the $\mathrm{pH}$ was re-measured and if the $\mathrm{pH}$ was higher than 7 the dust solutions were re-titrated. This procedure was repeated 2-4 times until dust solutions with $\mathrm{pH} 7$ or lower were derived.

To measure $\mathrm{CO}_{2}$ absorption capability, the dust solutions were placed in a $1000 \mathrm{ml}$ bubble column to which an air$\mathrm{CO}_{2}$ mixture $\left(30 \% \mathrm{CO}_{2} \mathrm{v} / \mathrm{v}\right)$ was fed at $298 \mathrm{~K}$. The $\mathrm{CO}_{2}$ concentration of the gas mixture was measured by a gas chromatograph (GC, Perkin Elmer Clarus 400) equipped with a TCD detector, prior to the $\mathrm{CO}_{2}$ absorption experiments, a series of samples with known $\mathrm{CO}_{2}$ concentrations 
were used to calibrate the TCD signal. The transient mass balance of the mini column was carried out to estimate the total $\mathrm{CO}_{2}$ captured by the solutions. In a typical procedure, $700 \mathrm{ml}$ of the dust solution was put in contact with a $150 \mathrm{ml} /$ min flow of gas mixture. Samples of the gas mixture were taken every $5 \mathrm{~min}$, and the flow of gas mixture was terminated when the $\mathrm{CO}_{2}$ concentration at the outlet of the column was the same as that at the inlet. As in the titration experiments, $\mathrm{CO}_{2}$ absorption was repeated 2, 3, or 4 times (at 24-h intervals) for some dust solutions until the $\mathrm{CO}_{2}$ concentration at the outlet remained constant after $24 \mathrm{~h}$ of aging.

\section{Results and Discussion}

As previously stated, EAF dust comprises $\mathrm{Ca}, \mathrm{Mg}, \mathrm{Na}$, and $\mathrm{K}$ (Table 2), and the oxides of these compounds react easily with water to produce hydroxides. For instance, $\mathrm{CaO}$ immediately interacts with wet air, thereby producing $\mathrm{Ca}$ $(\mathrm{OH})_{2}$. Hydroxides (strong alkali electrolytes) can also be dissolved in water to produce metal ions $\left(\mathrm{Ca}^{+2}, \mathrm{Mg}^{+2}, \mathrm{Na}^{+1}\right.$ and $\left.\mathrm{K}^{+1}\right)$ and hydroxyl ions $\left(\mathrm{OH}^{-}\right)$. Other metals high in dust such as $\mathrm{Fe}$ and $\mathrm{Zn}$ have a tendency to react easily with oxygen to produce the corresponding oxides; these oxides are not soluble in water and do not readily produce hydroxides. However, Fe and $\mathrm{Zn}$ oxides could be dissolved in alkaline solutions but their solubility decrease dramatically in neutral solutions. Moreover, complex oxides from $\mathrm{Fe}$ and $\mathrm{Zn}$ are found in the dust, as was exposed before, and their solubility under alkaline conditions is not yet reported. In this work, dust solutions were prepared, and the $\mathrm{pH}$ measurements attest the nature of the solutions. All the solutions were reddish-brown and contained suspended solids. In some cases, the $\mathrm{pH}$ was as high as 13 , indicating the presence of strong alkalis. Alkaline solutions can be corrosive and cause damage to human health. In industrial practices, EAF dust is sometimes pelletized, placed in open silos for storage, and then disposed of in landfills or sent to metal recovery facilities. Under such situations, the period at which the environment is exposed to dust depends on industrial protocols. If the dust is exposed to rain, there could be a possibility of environmental damage.

Table 1 shows the $\mathrm{pH}$ measured from all the fresh dust solutions ( $\mathrm{pH}$ measured under stirring). The results suggest that EAF dust reacts with water to produce hydroxides, after which $\mathrm{OH}^{-}$ions dissolve, thereby increasing the $\mathrm{pH}$. This phenomenon can be attributed to four metals: $\mathrm{Ca}, \mathrm{Mg}, \mathrm{Na}$, and K. Table 3 shows the concentrations of these metals and their corresponding $\mathrm{OH}^{-}$concentrations, which were determined under the assumption that $\mathrm{CaO}, \mathrm{MgO}, \mathrm{Na}_{2} \mathrm{O}$, and $\mathrm{K}_{2} \mathrm{O}$ are found in EAF dust. These components quickly produce hydroxides in the fresh solutions.

From samples 1 to 3 of the fresh solutions showed an increase in $\mathrm{pH}$, but samples 4-7 exhibited a comparable $\mathrm{pH}$ even as the dust concentration was the highest in sample 7. This result can be explained by the solubility of hydroxides (Table 3). For instance, sample 1 required $19 \mathrm{ml}$ of water ( $95 \mathrm{ml}$ of water $/ 5 \mathrm{~g}$ of dust) to dissolve the hydroxides and other compounds in $1 \mathrm{~g}$ of dust. The $\mathrm{OH}^{-}$concentrations of all the samples was estimated using ASPEN, and the results are shown in Table 1. The table indicates that the $\mathrm{OH}^{-}$con-
Table 3. $\mathrm{OH}^{-}$concentrations in EAF dust solutions, determined from metal hydroxide content and solubility of simple metal hydroxides.

\begin{tabular}{ccccc}
\hline Compound & $\begin{array}{c}\text { mol of hydroxides } \\
\text { possibly generated } \\
\text { from the metal } \\
\text { (mmol/kg of dust) }\end{array}$ & $\begin{array}{c}\text { mol ratio } \\
\text { OH/M of the } \\
\text { corresponding } \\
\text { hydroxide }\end{array}$ & $\begin{array}{c}\text { Theoretical } \mathrm{OH}^{-} \\
\text {ions available } \\
\text { (mmol of } \\
\mathrm{OH}^{-} / \mathrm{kg} \text { of dust) }\end{array}$ & $\begin{array}{c}\text { Solubility of } \\
\text { corresponding } \\
\text { hydroxide in } \\
\text { water (mmol of } \\
\text { M-(OH) })_{\text {per }} \\
\text { liter of water) }\end{array}$ \\
\hline $\mathrm{Ca}$ & 778.4 & 2 & 1556.8 & 24.97 \\
$\mathrm{Mg}$ & 1023.2 & 2 & 2046.4 & 0.02 \\
$\mathrm{Na}$ & 1600.9 & 1 & 1600.9 & 27750 \\
$\mathrm{~K}$ & 1049.6 & 1 & 1049.6 & 21210 \\
$\mathrm{Total}$ & & & 6253.7 & \\
\hline
\end{tabular}

$\mathrm{n}=1$ for $\mathrm{Na}$ and $\mathrm{K}, 2$ for $\mathrm{Ca}$ and $\mathrm{Mg}$

$\mathrm{M}=\mathrm{Ca}, \mathrm{Mg}, \mathrm{Na}$, or $\mathrm{K}$

centrations in the fresh solutions (for which $\mathrm{pH}$ was measured) were lower than those estimated using ASPEN and the electrolyte NRTL model. This discrepancy may be attributed to the fact that simple hydroxides and other soluble compounds present in the dust dissolve first and reach solubility limits. These phenomena were not observed in the ASPEN estimations because only $\mathrm{Ca}, \mathrm{Mg}, \mathrm{K}$, and $\mathrm{Na}$ as simple hydroxides were considered in the calculations, i.e. oxides and others were not included. In every case, these results suggest that strong basic solutions can be produced from EAF dust even at low dust concentrations. The origin and composition of EAF dust were discussed in previous research, ${ }^{6-8)}$ which show that simple and complex oxides are present in dust samples. Simple oxides and their corresponding hydroxides dissolve first until the fresh solutions are saturated. This feature can explain the slight differences between the $\mathrm{pH}$ of fresh samples 1-7.

Table 1 shows the concentration of bases (derived by titration with the $\mathrm{HCl}$ solution) of each fresh EAF dust solution. The concentrations were obtained by one round of titration for each solution. Conventional titration is useful because the volume of $\mathrm{HCl}$ used for neutralization can be converted into the $\mathrm{OH}^{-}$concentration in EAF dust solutions. Conventional acid-base titration is based on acid-base reactions, such as

$$
\begin{gathered}
\mathrm{H}^{+}+\mathrm{OH}^{-} \Rightarrow \mathrm{H}_{2} \mathrm{O} \\
M^{+x}+x \mathrm{Cl}^{-} \Rightarrow \mathrm{MCl}_{x}
\end{gathered}
$$

where $\mathrm{M}$ can represent $\mathrm{Ca}, \mathrm{Mg}, \mathrm{Na}$, and $\mathrm{K}$, and for these compounds, $x$ denotes $2,2,1$, and 1, respectively.

The results show that the amoung of bases corresponded to the EAF dust concentrations in the solutions. This phenomenon can be explained by the solubility limits of water and the hydroxide concentration in the EAF dust solutions. As previously discussed, the fresh EAF dust solutions dissolved bases until solubility limits were reached, indicating that some bases may be available but undissolved in dust solutions. When the $\mathrm{HCl}$ solution was added to the EAF dust solutions, water and metal salts were produced and the dust solutions recovered part of their ability to dissolve bases. These processes can recur until (a) water is saturated but the dissolution of new bases dominates; (b) water is totally sat- 
urated; or (c) metal oxides (and their corresponding hydroxides) are consumed.. After $24 \mathrm{~h}$ of aging with mixing, some additional bases were dissolved and more rounds of titration were needed. It is possible that during titration, more bases are dissolved until the mass transfer of becomes the dominant reaction. Note, however, that the titration conditions for each solution differed. For instance, four different rounds of $\mathrm{HCl}$ titration were required to completely neutralize sample 4 , but two rounds were sufficient for sample 1. Results of tritration were used for a roughly estimation of the amoung of $\mathrm{CO}_{2}$ the solution can absorb. Figure 1 compares the total amount of bases derived by titration and the concentration that would be obtained if only $\mathrm{NaOH}$ and $\mathrm{KOH}$ are dissolved (corresponding to $\mathrm{Na}$ and $\mathrm{K}$ content; $\mathrm{Ca}$ and $\mathrm{Mg}$ were disregarded in the estimation because they exhibited the lowest solubility). In all the samples, the total bases concentration estimated by titration was less than that estimated under the $\mathrm{NaOH} / \mathrm{KOH}$ scenario; $85 \%$ (on average) of the hypothetical bases were measured. This expected feature is attributed to the exclusion of more complex oxides in the calculation shown in Fig. 1. For example, highly stable mixed oxides, such as $\mathrm{MgFe}_{2} \mathrm{O}_{4}$, could be found in the EAF dust and their contributions were lower than that of the corresponding $\mathrm{MgO}$ simple oxide. Moreover, $\mathrm{Ca}$ and $\mathrm{Mg}$ have low solubility. In such cases, the correlation between $\mathrm{NaOH}$ and $\mathrm{KOH}$ and the concentration of bases estimated by titration suggests that the high $\mathrm{pH}$ of the EAF dust solutions is related to the $\mathrm{Na}$ and $\mathrm{K}$ content in dust. The aforementioned hypothesis is useful because in industrial practices, only $\mathrm{Ca}$, $\mathrm{Mg}, \mathrm{Na}$, and $\mathrm{K}$ are easily detected by simple equipment. The results of the study are expected to facilitate the convenient estimation of $\mathrm{OH}^{-}$and bases content in solutions that contain EAF dust.

Finally, $\mathrm{CO}_{2}$ capture was carried out for all the samples (derived from the fresh samples), as described in the experimental section. The conditions of the absorption experiment on all the samples were the same; that is, the final $\mathrm{CO}_{2}$ captured was, on average, $1.52 \times 10^{-3} \mathrm{~mol}$ of $\mathrm{CO}_{2} / \mathrm{g}$ of dust in the solutions (standard deviation, $0.08 \times 10^{-3}$ in respective units). The differences between the $\mathrm{CO}_{2}$ captured from samples 1-7 were the factors used to determine the manner by which total saturation with $\mathrm{CO}_{2}$ was carried out; that is, the high-dust samples required more rounds of saturation simi-

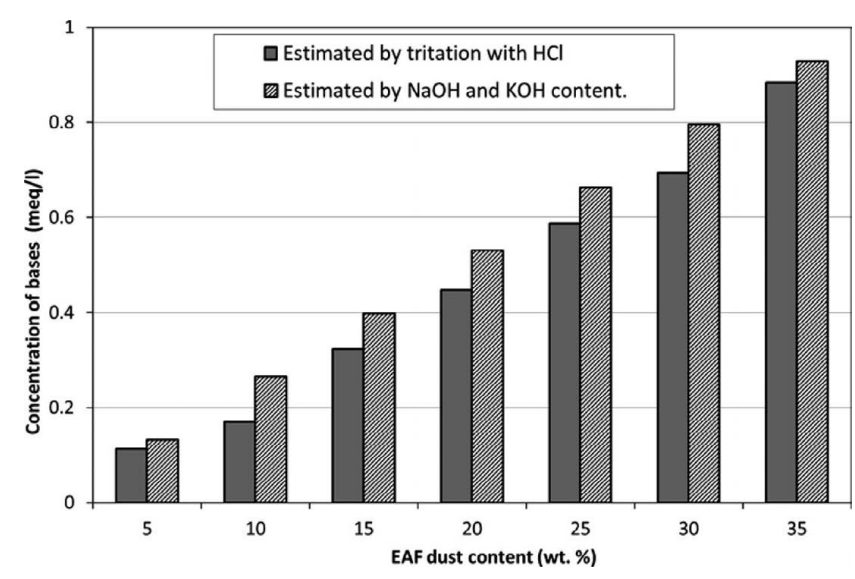

Fig. 1. Concentration of bases of the solutions with several dust content. lar to the requirement in the $\mathrm{HCl}$ titration experiments. $\mathrm{CO}_{2}$ can be dissolved in water to produce $\mathrm{H}_{2} \mathrm{CO}_{3}$, and this weak acid reacts with a base as follows:

$$
\mathrm{H}_{2} \mathrm{CO}_{3}+\frac{2}{y} \mathrm{M}(\mathrm{OH})_{y} \Rightarrow \mathrm{M}_{z} \mathrm{CO}_{3}+\mathrm{H}_{2} \mathrm{O}
$$

where $\mathrm{M}$ can represent $\mathrm{Ca}, \mathrm{Mg}, \mathrm{Na}$, and $\mathrm{K}$; for these compounds, $y$ denotes $2,2,1$, and 1 , respectively, and $z$ denotes $1,1,2$, and 2 , respectively.

The last general reaction shows that each $\mathrm{CO}_{2}$ mole reacted with two hydroxyls to produce a mole of metal carbonate and water. However, it is know that $\mathrm{CO}_{2}$ is absorbed mainly as $\mathrm{CO}_{2}^{-2}$ (carbonate) when $\mathrm{pH}>10$ and mainly as $\mathrm{HCO}_{2}{ }^{-1}$ (bicarbonate) when $7<\mathrm{pH}<9$; this indicate that the amount of bases does not show linearly with the $\mathrm{CO}_{2}$ absorbed. Usually mole of $\mathrm{CO}_{2}$ used for neutralize is less than mole of $\mathrm{HCl}$ required for neutralize alkaline solutions. Therefore, the $\mathrm{CO}_{2}$ captured was in agreetment with this. To illustrate, on the basis of the solubility of $\mathrm{CO}_{2}$ in water (Henry's law constant $=1640 \mathrm{~atm}$ at $298 \mathrm{~K}$ ) and the titration results under assumption that mole of $\mathrm{CO}_{2}$ is the same that mole de $\mathrm{HCl}$ used for neutralization, $100 \mathrm{~g}$ of sample 4 result in $3.33 \times$ $10^{-2} \mathrm{~mol}$ of $\mathrm{CO}_{2}$ captured $\left(8.1315 \times 10^{-4} \mathrm{~mol}\right.$ of $\mathrm{CO}_{2}$ dissolved in $80 \mathrm{~g}$ of water $+2.21 \times 10^{-3} \mathrm{~mol}$ of $\mathrm{CO}_{2} / \mathrm{g}$ of dust* $15 \mathrm{~g}$ of dust $=\mathrm{mol}$ of $\mathrm{CO}_{2}$ captured by $100 \mathrm{~g}$ of sample 4). The experimental results showed that $100 \mathrm{~g}$ of sample 4 captured $2.22 \times 10^{-2} \mathrm{~mol}$ of $\mathrm{CO}_{2}$.

\subsection{Process of EAF Dust Neutralization by $\mathrm{CO}_{2}$ from EAF (Brief Description)}

The capacity of EAF dust to adsorb $\mathrm{CO}_{2}$ can be useful in steel plant operations for two reasons: (a) $\mathrm{CO}_{2}$ capture and (b) treatment of EAF dust to decrease the alkaline properties of such dust at the same time that this material is produced. The process is represented in Fig. 2. Under fusion and liquid steel refinement, high-temperature gases $(\sim 1873 \mathrm{~K})$ with dust are extracted from an EAF. These components then mix with air to induce reaction with the remaining $\mathrm{CO}$ to produce $\mathrm{CO}_{2}$, after which the gas-dust-air mixture is fed into a separation chamber where large particles are separated from the gases and fine particles. Large particles are periodically recovered and introduced to sedimentation equipment. Gases with fine particles are fed into equipment where solutions containing dust are sprayed directly onto the gases; this is the most important step in the process because the spraying solution captures $\mathrm{CO}_{2}$, removes new dust particles, and cools gases. The gases with low dust content are transported to baghouses and the dust solution is recovered. At this stage, metal oxides react with water and $\mathrm{CO}_{2}$, thereby producing carbonates. The solution that contains dust and carbonates is fed into a stirrer tank, to which fresh water and dust are also fed to maintain $\mathrm{pH}$ of spray solution. Some of the solution from the stirrer tank is transported to the sedimentation equipment where water is recovered and recirculated, whereas the sediment dust with carbonates but without alkaline properties is sent to disposal.

This process can capture up to $66 \mathrm{~kg}$ of $\mathrm{CO}_{2} /$ ton of EAF dust. Aside from requiring simple equipment, a number of other advantages are presented by such process: dust from flue gases are pretreated (neutralized), $\mathrm{CO}_{2}$ is captured, and dioxin production may be avoided. 


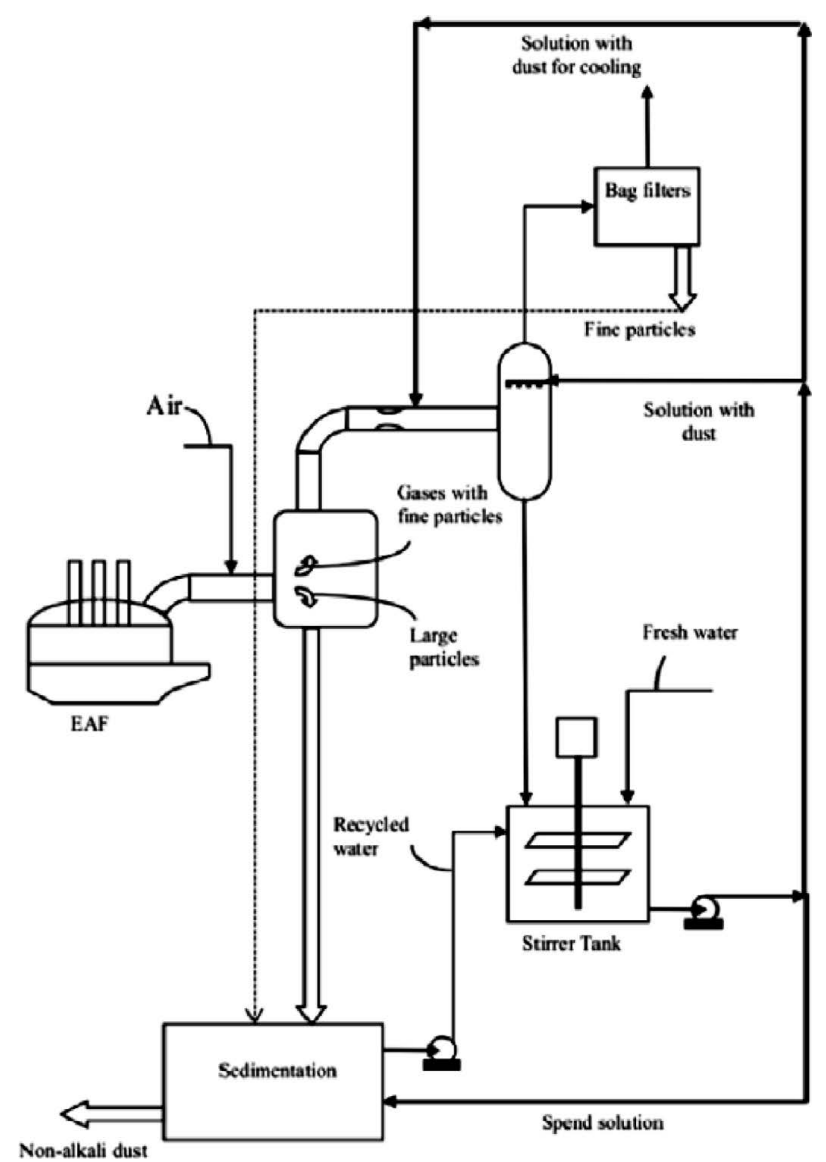

Fig. 2. Simultaneous $\mathrm{CO}_{2}$ capture and dust neutralization.

\section{Conclusion}

The properties that enable the use of EAF dust in the production of alkali solutions with high $\mathrm{pH}(\sim 14)$ were evaluated by the synthesis of solutions with different dust concentrations. The results suggest that metal oxide content (aside from heavy metal content) can be considered in the handling and disposal of EAF dust because metal oxides quickly react with water to produce alkalis.
The solutions used in the study were titrated with $\mathrm{HCl}$ and with $\mathrm{CO}_{2}$ to determine the possibility of simultaneous $\mathrm{CO}_{2}$ capture and dust neutralization. The EAF dust solutions captured $\mathrm{CO}_{2}$, thereby demonstrating their potential as materials with a dual purpose: decreasing $\mathrm{CO}_{2}$ emission and neutralizing the alkaline properties of EAF dust solutions.

The process that capitalizes on EAF dust properties was described with a simple diagram of high functionality (Fig. 2). The process also features a step wherein the gases from an EAF are cooled and dust is removed to minimize the possibility of dioxin formation.

\section{REFERENCES}

1) C. A. Pickles: Sep. Purif. Technol., 59 (2008), 115.

2) C. A. Pickles: J. Hazard. Mater., 166 (2009), 1030.

3) C. P. Manning and R. J. Fruehan: JOM, 53 (2001), 36.

4) Y. N. Toulouevski and I. Y. Zinurov: Innovation in Electric Arc Furnaces: Scientific Basis for Selection, Springer, Heidelberg, New York, (2010).

5) E. Trejo, F. Martell, O. Micheloud, L. Teng, A. Llamas and A. Montesinos-Castellanos: Energy, 42 (2012), 446.

6) N. Tsubouchi, H. Hashimoto, N. Ohtaka and Y. Ohtsuka: J. Hazard. Mater., 183 (2010), 116.

7) J. G. M. S. Machado, F. A. Brehm, C. A. M. Moraes, C. A. D. Santos, A. C. F. Vilela and J. B. M. D. Cunha: J. Hazard. Mater., 136 (2006), 953.

8) A. G. Guézennec, J. C. Huber, F. Patisson, P. Sessiecq, J. P. Birat and D. Ablitzer: Powder Technol., 157 (2005), 2.

9) M. T. Hepworth, J. K. Tylko and H. Han: Waste Manage. Res., 11 (1993), 415.

10) A. D. Zunkel: Iron Steel Eng., 74 (1997), 33.

11) K.-H. Bauer, D. Huette, H.-J. Lehmkuehler and H. Schmauch: Metall. Plant Technol., 13 (1990), 7.

12) T. Funahashi, A. Kaikake and T. Sugiura: Proc. of 1998 TMS Annual Meeting, Minerals, Metals \& Materials Society, Warrendale, PA, (1998), 487.

13) N. De Goicoechea y Gandiaga and B. Garcia-Egocheaga Vergara: Proc. of the TMS Fall Extraction and Processing Conf., Global Symp. on Recycling, Waste Treatment and Clean Technology (REWAS 1999), Warrendale, PA, (1999), 1511.

14) J. F. Pusateri, C. O. Bounds and L. W. Lherbier: JOM-J. Min. Met. Mat. S., 40 (1988), 31.

15) H. W. Ma, K. Matsubae, K. Nakajima, M. S. Tsai, K. H. Shao, P. C. Chen, C. H. Lee and T. Nagasaka: Resour. Conserv. Recycl., 56 (2011), 134.

16) G. Salihoglu and V. Pinarli: J. Hazard. Mater., 153 (2008), 1110.

17) M. Liebman: Proc. of the TMS Fall Extraction and Processing Conference, 4th Int. Symp. on Recycling of Metals and Engineered Materials, Warrendale, PA, (2000), 237.

18) R. L. Nyirenda: Miner. Eng., 4 (1991), 1003.

19) M. Cruells, A. Roca and C. Núnẽz: Hydrometallurgy, 31 (1992), 213. 